\title{
Evaluation of the impact of food technology on the allergenicity of cow's milk proteins
}

\author{
M. Heyman \\ INSERM E9925, Faculté de médecine Necker-Enfants malades, 156 rue de Vaugirard, 75730 Paris, France
}

\begin{abstract}
The quantitative evaluation of the allergenicity of food proteins and the clinical tolerance towards antigens are problems the food industry and the clinicians have to face. The allergenicity of a protein depends on multiple factors, including the stability to digestion and the interaction with the intestinal environment. In addition to the possible reduction in allergenicity by technological treatments such as heat and enzymic hydrolysis, the complex interactions existing between the antigens, the intestinal epithelium and the underlying immune system, as well as the individual susceptibility to the sensitizing epitopes, have to be taken into account. Indeed, the intestinal cells are able to take up and process proteins, and possibly to present them directly to mucosal lymphocytes. On the other hand, pathophysiological conditions can modify the interactions between food antigens and the immune system. A large number of methods has been developed to assess the residual antigenicity of food proteins, based on the various immune responses leading to intestinal or extradigestive pathologies. Thus, the difficulty in measuring the residual allergenicity of hypoallergenic formulas is partly due to the physiology of the gastrointestinal tract, since an intricate network of interactions between enterocytes and immune cells governs the development of the immune response to food antigens.
\end{abstract}

\section{Résumé}

\begin{abstract}
L'évaluation de l'allergénicité des aliments et leur bonne tolérance clinique est une question touchant à la fois les industriels de l'agro-alimentaire et les cliniciens. L'allergénicité d'une protéine dépend de multiples facteurs parmi lesquels la résistance à la digestion, les interactions avec le tractus digestif et les facteurs environnementaux. L'allergénicité d'un produit alimentaire peut être modifiée non seulement par les traitements technologiques industriels, mais aussi par le tractus gastrointestinal. La susceptibilité individuelle aux epitopes peptidiques formés est également un facteur primordial. En effet, les interactions complexes existant entre les antigènes, l'épithelium intestinal et le système immunitaire muqueux peuvent conduirent à des réponses immunitaires différentes selon les individus. De nombreuses méthodes existent pour mesurer l'antigénicité résiduelle des aliments, basées sur la nature des différentes réactions immunitaires anormales conduisant à une pathologie intestinale ou extradigestive. La difficulté de mesurer l'allergénicité résiduelle de formules hypoallergéniques repose donc sur les relations complexes entre les antigènes alimentaires, l'épithelium intestinal et le système immunitaire muqueux.
\end{abstract}

Food allergy: Hypoallergenicity: Infant formula: Food protein processing: Cow's milk

Adverse reactions to food are relatively frequent, and affect mainly the digestive tract but also many other organs, explaining the variety of symptoms observed. They are divided into toxic and non-toxic reactions, the latter being divided into immune-mediated (allergy) and non-immunemediated (intolerance) reactions. Food allergy develops when the intestinal immune system does not respond normally to the exogenous food proteins or protein fragments which have escaped lumen hydrolysis. Although a strong mucosal immune response is generally developed against enteric pathogens such as viruses or bacteria, the passage of large amounts of incompletely degraded food

\footnotetext{
Abbreviations: CMA, cow's milk allergy; Ig, immunoglobulin; MHC, major histocompatibility complex.
}

Corresponding author: Dr Martine Heyman, fax +331 406156 38, email heyman@ necker.fr 
proteins in the intestine normally does not stimulate an immune response. This apparent lack of response to food antigens is termed oral tolerance, and can be achieved by active processes such as clonal anergy, clonal deletion or bystander suppression (Weiner, 1994). In some instances, the mucosal immune system develops abnormal responses to food proteins, leading to local allergic inflammation, often altering the intestinal function.

Such allergic responses are mediated by different mechanisms involving either humoral factors such as immunoglobulin (Ig) E or immune complexes, or cellular factors including T-cells.

\section{Development of food allergy: a multifactorial process}

Among the confounding factors responsible for the development of food allergy, genetic and environmental factors play important roles, together with factors linked to the intestinal absorption and processing of the protein. Genetic factors include the atopic syndrome, manifesting as the hereditary propensity to develop IgE-mediated allergies. Some proteins (e.g. $\beta$-lactoglobulin and lactotransferrin) are known to be resistant to acid- and enzymic hydrolysis in the lumen. The stability of food allergens to digestion has been suggested as a significant and valid variable that distinguishes food allergens from non-allergens (Astwood et al. 1998). Another problem is the generation of new allergenic determinants during food processing or during intestinal digestion (Ju et al. 1997). In addition, evidence showing that the development of oral tolerance to food antigens is linked to intestinal processing by the epithelial intestinal cells has been reported (Fargeas et al. 1995; Troncone et al. 1996). A normal uptake and processing of the antigen by the intestinal epithelial cells seems mandatory to the development of oral tolerance, since alterations of the epithelial barrier can lead to an abnormal immune response to food antigens: in a guinea-pig model of cow's milk allergy, the presence of a sulphonic acid-induced colitis led to the enhancement of the milk-protein-induced anaphylaxis (Fargeas et al. 1995), and a graft $v$. host enteropathy in mice was associated with a defective gut processing of gliadin, and a failure in oral tolerance induction (Troncone et al. 1996). Thus, considering the multiple ways by which the immune system can 'see' a food antigen, it can be expected that the measurements of the potential allergenicity of a food protein will be complex and will involve multiple assays.

\section{Immune mechanisms of food allergy}

Immune reactions are mediated by antibodies and cells in an intricate network of interactions. Antibodies of the $\operatorname{IgE}$ class have a key role in atopic allergic reactions, and $\mathrm{T}$ lymphocytes have a regulatory role by providing stimulatory (T-helper) and damping (T-suppressor) effects. Coombs \& Gell (1968) proposed a classification of immune reactions according to four types. However, two main types have been extensively studied, the type I reaction consisting of atopic IgE-dependent reactions and the type IV reaction involving T-cell-mediated delayed hypersensitivity. It is not clear at which sites B-cells are induced to produce specific $\operatorname{IgE}$ but, once produced, circulating $\operatorname{IgE}$ molecules can bind to receptors on basophils, mast cells or eosinophils. Secondary exposure to antigen causes cross-linkage of $\operatorname{IgE}$ and degranulation of these cells. These events occur sometimes at the systemic level but most often in the gastrointestinal tract, and the release of inflammatory mediators leads to alterations in normal gut function.

Allergic reactions often develop in patients without evidence of atopy or high levels of specific IgE. In those patients, adverse reactions generally have a slow onset and are mediated through activation of T-cells. Cow's milksensitive enteropathy and gluten-induced enteropathy are examples of such cell-mediated adverse reactions. In these pathologies, the activation of CD4+ T-cells can be reproduced in vitro by exposing biopsies or peripheral blood mononuclear cells to the offending antigens. Activated T-cells generally have a T-cell receptor $\alpha / \beta$ showing a molecular restriction that matches the genetic predisposition to antigen-sensitive enteropathy, a well described phenomenon in coeliac disease (Sollid et al. 1989).

\section{Influence of technological treatments on allergenicity: the case of infant milk formulas}

When breast-feeding is stopped, cow's milk-based formulas are most commonly used to feed human infants. As cow's milk allergy (CMA) develops in $3 \%$ of the paediatric population, milk manufacturers have had to face the problem of reducing cow's milk protein antigenicity (Hudson, 1995). Treatment by heat denatures the protein and conformational epitopes (although casein is relatively heat stable), but has only a moderate effect on the allergenicity of the proteins (Höst \& Samuelsson, 1988). Some epitopes can also be destroyed by enzymic cleavage. Indeed, an in vitro tryptase (EC 3.4.21.59) hydrolysate of whey proteins was devoid of sensitizing capacity by the oral route in a guinea-pig model of cow's milk allergy (Pahud et al. 1985). There are two main types of infant formulas available for the prevention or treatment of cow's milk allergy. Partially-hydrolysed formulas, in which the number of large-molecular-mass molecules is reduced, are generally used to prevent allergic reactions in susceptible individuals, but they are not strictly hypoallergenic, since important allergic responses or anaphylactic reactions (Businco et al. 1994) have been reported. Extensively-hydrolysed formulas are derived from casein or whey proteins and used to treat children with CMA. These formulas normally do not contain any residue of molecular mass > $1500 \mathrm{Da}$. Among children with CMA, $10 \%$ are still allergic to extensively-hydrolysed formulas (de Boissieu et al. 1997), and are treated sucessfully with amino acid-based formulas.

\section{Influence of the intestinal tract in the modification of food proteins}

The vast majority of ingested dietary antigens are degraded by the lumen hydrolytic system. However, a small proportion are resistant to digestive enzymes and reach the small intestine in macromolecular form (Mahé et al. 1991), and are available for intestinal absorption. To identify the precise role of the intestinal epithelium in antigen absorption and processing, in vitro studies have been developed in 
isolated fragments of intestine mounted in Ussing chambers. ${ }^{14} \mathrm{C}$ or ${ }^{3} \mathrm{H}$ radiolabelled proteins placed in the mucosal compartment are taken up and transported to the serosal side of the tissue. Most of the macromolecular protein which is taken up by the enterocyte is degraded in the endolysosomal compartment into amino acids (50\%) and peptides (40\%), the remaining $10 \%$ totally escapes degradation and is transported intact (Heyman et al. 1982; Terpend et al. 1998). Paracellular leakage across the tight junctions is not observed under physiological conditions, even at sites of cell desquamation (Madara, 1990), but pathological conditions, including bacterial infections (Heyman et al. 1989) or inflammatory mediators (Rodriguez et al. 1995), can lead to a paracellular leakage of antigens through the tight junctions. In addition, inflammatory mediators such as interferon- $\gamma$ are able to stimulate the transcellular process and increase the peptide load to the mucosa (Terpend et al. 1998).

Under physiological conditions, the amount of antigenic material transported by the intestinal epithelium is very small (approximately $2 \mu \mathrm{g} / \mathrm{h}$ per $\mathrm{cm}^{2}$ ), but it represents a constant stimulation to the underlying immune system (Heyman \& Desjeux, 1997). Interestingly, enterocytes, like professional antigen-presenting cells, are able to express major histocompatibility complex (MHC) class II molecules, mainly during inflammation. This finding suggests that the enterocyte can directly present peptidic epitopes to the $\mathrm{T}$ lymphocytes present in the mucosa. An efficient presentation has been described in vitro, but no clear evidence has been reported in vivo. The role of MHC class II molecules in antigen transcytosis and processing by the enterocyte is not known, but it is possible that the peptides formed during transcytosis are protected from total degradation and exposed, together with MHC class II molecules, to the enterocyte basal surface in order to stimulate underlying lymphocytes (Fig. 1). Alternatively, the small amount of intact antigen crossing the epithelial layer might be taken up and presented by professional antigen-presenting cells in the lamina propria. It is noteworthy that the type of immune response to an antigen (IgE hypersensitivity or T-cell activation) depends on the peptide structure or on the human leucocyte-associated antigen

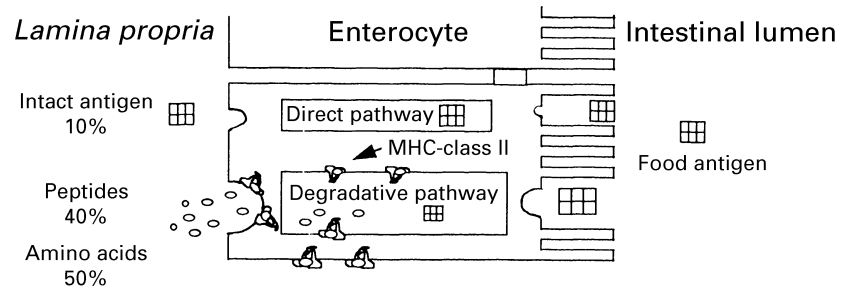

Fig. 1. The intestinal epithelial cell is a polarized cell which is able to take up undegraded food antigens present in the intestinal lumen. A transcellular transport occurs by transcytosis and most of the antigen is degraded within the endosomolysosomal system (transport rate is about $2 \mu \mathrm{g} / \mathrm{h} \mathrm{per} \mathrm{cm}^{2}$ ), while a small part is transported directly in an intact form (about $0.2 \mu \mathrm{g} / \mathrm{h}$ per $\mathrm{cm}^{2}$ ). Under inflammatory conditions, the transcytosis increases (Terpend et al. 1998) and major histocompatibility complex (MHC) class II molecules are expressed by the enterocyte and could interfere with the degradation of peptidic epitopes and the presentation of those peptides to underlying lymphocytes. (MHC class II and peptide. haplotype, at least where conventional antigen-presenting cells are concerned (Soloway et al. 1991).

Thus food proteins apparently follow a succession of structural modifications, from the treatment by the food industry to the degradation by digestive enzymes and further processing by the intestinal epithelial cell. Thus, it seems reasonable to state that the allergenicity of an antigen cannot be predicted by the analysis of the crude product, but that physiological bases of antigen transport and modification by the organism also have to be taken into account.

\section{Evaluation of the allergenicity of food proteins}

Due to the diversity of immune responses leading to food allergy, a variety of procedures for predictive testing of food antigens has been developed. They can be placed into one of the three categories: (1) detection of residual antigenic fragments, (2) antibodies to food antigens ( $\operatorname{IgE}, \operatorname{IgG}$ ) and release of immune mediators by sensitized cells (histamine, tryptase, eosinophil cationic protein and tumour necrosis factor $\alpha$ ) and (3) lymphocyte proliferation. Ultimately, the most efficient testing of the allergenicity should be by the controlled oral provocation of allergic subjects, although large variations are expected due to individual susceptibility of patients, and of course problems of safety have to be considered.

Residual antigenic fragments are generally detected by SDS-PAGE followed by immunoblotting, or HPLC. Among the various hypoallergenic milk-derived infant formulas, partially-hydrolysed formulas present a higher quantity of protein material, distributed over a wide range of molecular masses, while extensively-hydrolysed formulas show a lower level of residue, often concentrated in only a few bands in SDS-PAGE (Restani et al. 1996). This finding explains why, in extremely-sensitized patients, extensivelyhydrolysed formulas are not efficient in the treatment of CMA.

The capacity to stimulate antibody formation can be tested by in vivo antigenicity assays. Parenteral application of the test protein to laboratory animals can be used to determine specific immune responses, but this technique bypasses natural barriers such as gastrointestinal denaturation and processing by epithelial cells, limiting the usefulness of this test.

Residual antigenicity of hypoallergenic infant formulas can also be tested by the measurement of specific IgE or IgG in sera from patients with clinical allergy, using ELISA, radioallergosorbent test or by radioallergosorbent inhibition tests (Oldaeus et al. 1991; Wahn et al. 1992; van Beresteijn et al. 1995).

For the detection of peptides carrying plurivalent epitopes (a condition necessary to trigger the bridging of antigen-specific IgE on mast cells or basophils) other assays have been used. They include in vitro testing of the degranulation of sensitized mast cells or basophils by the release of various mediators including histamine, serotonin (Fritsché \& Bonzon, 1990), specific hydrolases tryptase or chymase (EC 3.4.21.39; Ju et al. 1997), or measurements in vivo such as fatal systemic anaphylactic reactions or passive cutaneous anaphylaxis in experimental animals (Anderson et al. 1979). 
Another way to assess mast cell degranulation consists of measuring the effect on a biological function of the mediators released on antigen stimulation. Indeed, in intestinal fragments from cow's milk-sensitized guinea-pigs mounted in Ussing chambers, the stimulation of the serosal side of the tissue with $\beta$-lactoglobulin induces a rise in short-circuit current (Heyman et al. 1990; Kitagawa et al. 1995; Fig. 2), an index of the electrogenic Cl-secretion induced in intestinal epithelial cells by mast cell mediators (histamine, prostaglandins, adenosine and serotonin etc.). Conversely, anaphylactic sensitization of guinea-pigs drinking different preparations of cow's milk and infant formulas showed that the manufacturing process (evaporated, spray-dried or liquid-concentrate milks) has an important impact on the sensitization process (Anderson et al. 1979). By contrast, microbial acidification by different lactic acid bacteria has a negligible effect on cow's milk allergenicity (Pahud \& Schwarz, 1985).

In human subjects, skin-prick tests can be considered as markers of IgE-mediated local inflammatory reactions. It has often been observed that IgE-mediated reactions to food proteins are not representative of all types of clinical reaction in allergic patients. Indeed, a number of children with CMA do not present high titres of total or specific IgE against cow's milk antigens, but rather T-cell-mediated delayed reactions, and reliable tests to analyse the peptidic epitopes responsible for such an activation are lacking. In vitro lymphocyte proliferation in the presence of milk antigens has been used as a marker of delayed T-cell-mediated hypersensitivity (type IV). There are some questions as to the value of this test in the diagnosis of CMA, but it could be used to affirm the absence of immunogenicity of hydrolysed

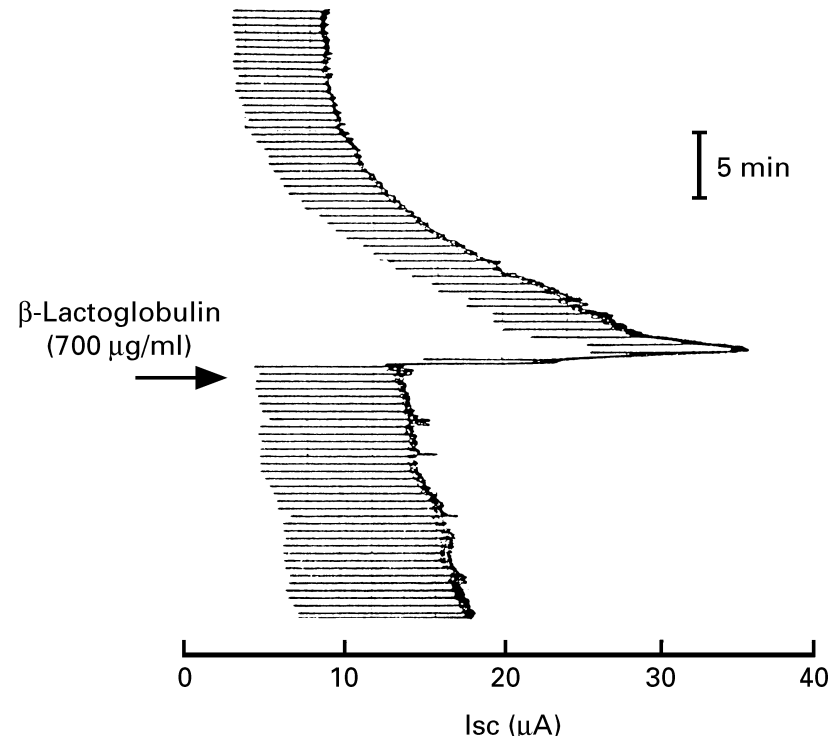

Fig. 2. In order to measure sensitization to milk proteins, in vitro responses of the intestinal epithelium to the milk antigen $\beta$-lactoglobulin can be measured in Ussing chambers. The intestinal fragment is mounted as a flat sheet between two half chambers and serosal stimulation with $\beta$-lactoglobulin $(700 \mu \mathrm{g} / \mathrm{ml})$ induces an increase in short-circuit current (ISC), an index of chloride ion secretion. Chloride ion secretion is stimulated by mucosal mast cell degranulation and the release of mediators acting on basal receptors of enterocytes. milk formulas (Eigenmann et al. 1995). Since it was observed that the 'patch test' elicited delayed-type hypersensitivity reactions, this cutaneous test was used to diagnose CMA with slow-onset clinical reactions (Isolauri \& Turjanmaa, 1996). It is possible that patch tests could help in the determination of T-cell epitopes in hydrolysed milk formulas.

Recently, we presented results on the importance of tumour necrosis factor $\alpha$ secretion in the pathogenesis of CMA (Heyman et al. 1994). Indeed, in the presence of intact milk proteins or antigenic fragments, peripheral blood mononuclear cells from children with CMA specifically secreted high amounts of tumour necrosis factor $\alpha$ (Fig. 3), and the threshold of immune reactivity was greatly decreased compared with that of children who had recovered from CMA (Fig. 3; Benlounes et al. 1996). It was further shown that this tumour necrosis factor $\alpha$ secretion was high after $1 \mathrm{~d}$ in children with immediate skin or digestive symptoms, whereas it was high after $5 \mathrm{~d}$ in children with delayed digestive symptoms (N Benlounes, $\mathrm{C}$ Candalh, P Matarazzo, C Dupont and M Heyman, unpublished results). Thus, this test might be used to detect allergenic epitopes recognized by $\operatorname{IgE}$ (day 1 test) or by T-cells (day 5 test). It has been used sucessfully to assess the hypoallergenicity of extensively-hydrolysed infant formulas (Fig. 4; Heyman et al. 1997).

\section{Conclusion}

In conclusion, food technology has the capacity to modify the antigenicity and allergenicity of food proteins. In rare instances technological treatment can increase their allergenicity (by release of new allergenic epitopes by

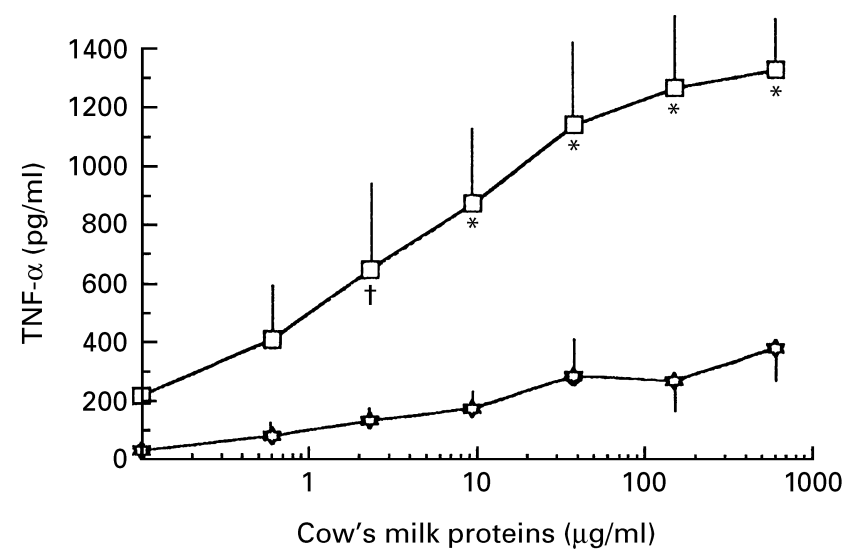

Fig. 3. Tumour necrosis factor $\alpha$ (TNF- $\alpha$ ) secretion by peripheral blood mononuclear cells from children with active cow's milk allergy $(\square)$ has been shown to reflect the extent of sensitization to cow's milk protein (Benlounes et al. 1996). A high TNF- $\alpha$ secretion is observed even in the presence of minute amounts of intact milk protein (approximately $1 \mu \mathrm{g} / \mathrm{ml}$ ) and the response increases with the antigen load. In children having acquired oral tolerance ( $\downarrow$ ) TNF- $\alpha$ secretion remains low, even at high antigenic concentrations. These results indicate that very low amounts of antigenic proteins can trigger abnormal immune reactivity in allergic children. Values are means with their standard errors represented in vertical bars. Mean values were significantly different from those for children who had recovered from CMA: $* P<0.03, \dagger P=0.07$. 


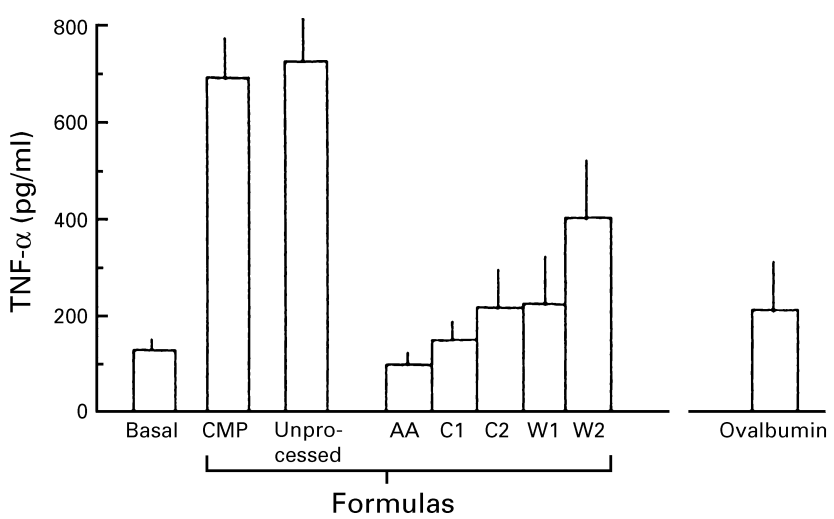

Fig. 4. Tumour necrosis factor $\alpha$ (TNF- $\alpha$ ) secretion by peripheral blood mononuclear cells after $24 \mathrm{~h}$ culture in vitro, has been used to compare the hypoallergenicity of various milk-derived infant formulas (Heyman et al. 1997). The condition 'basal' represents the basal TNF- $\alpha$ secretion in the absence of antigenic stimulation. CMP, a mixture of cow's milk proteins ( $\beta$-lactoglobulin $+\alpha$-lactalbumin + casein, each at $50 \mu \mathrm{g} / \mathrm{ml}$ ). The unprocessed formula is $S M A^{\circledR}$ (Sodilac). AA, amino acid-based formula (Neocate ${ }^{\circledR}$; SHS International); C1, casein hydrolysate 1 (Nutramigen ${ }^{\circledR}$; Mead-Johnson); C2, casein hydrolysate 2 (Pregestimil ${ }^{\circledR} ;$ Mead-Johnson); W1, whey-protein hydrolysate (Peptijunior $^{\circledR}$; Nutricia); W2, whey-protein hydrolysate 2 (Alfaré $^{\circledR}$; Nestlé). Values are means with their standard errors represented by vertical bars.

enzymic cleavage), but most often efficient methods have been developed to produce hypoallergenic products, such as extensively-hydrolysed infant formulas, whose efficacy in the treatment of allergic patients has been widely demonstrated. The difficulties of measuring the residual antigenicity of such formulas relate to the physiology of the gastrointestinal tract. Indeed, the intestinal epithelial compartment is involved in the degradation and processing of food antigens, and an intricate network of interactions between enterocytes and underlying immune cells governs the type of immune response.

\section{References}

Anderson KJ, McLaughlan P, Devey ME \& Coombs RR (1979) Anaphylactic sensitivity of guinea-pigs drinking different preparations of cows' milk and infant formulae. Clinical and Experimental Immunology 35, 454-461.

Astwood JD Leach JN \& Fuchs RL (1998) Stability of food allergens to digestion in vitro. Nature Biotechnology 14, 1269-1273.

Benlounes N, Dupont C, Candalh C, Blaton MA, Darmon N, Desjeux JF \& Heyman M (1996) The threshold for immune cell reactivity to milk antigens decreases in cow's milk allergy with intestinal symptoms. Journal of Allergy and Clinical Immunology 98, 781-789.

Businco L, Lucenti P, Arcese G, Ziruolo G \& Cantani A (1994) Immunogenicity of a so-called hypoallergenic formula in at-risk babies: two case reports. Clinical and Experimental Allergy 24, $42-45$.

Coombs RRA \& Gell PGH (1968) Clinical Aspects of Immunology. Oxford: Blackwell Scientific.

de Boissieu D, Matarazzo P \& Dupont C (1997) Allergy to extensively hydrolyzed cow milk proteins in infants: identification and treatment with an amino acid-based formula Journal of Pediatrics 131, 744-747.
Eigenmann PA, Belli DC, Lündi F, Kahn JM \& Polla BS (1995) In vitro lymphocyte proliferation with milk and a casein-whey protein hydrolyzed formula in children with cow's milk allergy. Journal of Allergy and Clinical Immunology 96, 549557.

Fargeas MJ, Theodorou V, More J, Wal JM, Fioramonti J \& Bueno L (1995) Boosted systemic immune and local responsiveness after intestinal inflammation in orally sensitized guinea pigs. Gastroenterology 109, 53-62.

Fritsché R \& Bonzon M (1990) Determination of cow milk formula allergenicity in the rat model by in vitro mast cell triggering and in vivo IgE induction. International Archives of Allergy and Applied Immunology 93, 289-293.

Heyman M, Andriantsoa M, Crain-Denoyelle AM \& Desjeux JF (1990) Effect of oral or parenteral sensitization to cow's milk on mucosal permeability in guinea pigs. International Archives of Allergy and Applied Immunology 92, 242-246.

Heyman M, Benlounes N, Candalh C \& Dupont C (1997) Evaluation of hypoallergenicity of various infant formula using $\mathrm{TNF} \alpha$ released from mononuclear cells of cow's milk allergic children. Journal of Pediatric Gastroenterology and Nutrition 24, 468 Abstr.

Heyman M, Corthier G, Lucas F, Meslin JC \& Desjeux JF (1989) Evolution of the caecal epithelial barrier during Clostridium difficile infection in the mouse. Gut 30, 1087-1093.

Heyman M, Darmon N, Dupont C, Dugas B, Hirribaren A, Blaton MA \& Desjeux JF (1994) Mononuclear cells from infants allergic to cow's milk secrete tumor necrosis factor alpha, altering intestinal function. Gastroenterology 106, 1514 1523.

Heyman M \& Desjeux J (1997) Antigen handling by intestinal epithelial cells. In Antigen Presentation by Intestinal Epithelial Cells, pp. 1-16 [D Kaiserlian, editor]. Heidelberg: Springer Verlag.

Heyman M, Ducroc R, Desjeux JF \& Morgat JL (1982) Horseradish peroxidase transport across adult rabbit jejunum in vitro. American Journal of Physiology 242, G558-G564.

Höst A \& Samuelsson EG (1988) Allergic reactions to raw, pasteurized, and homogenized/pasteurized cow milk: a comparison. A double-blind placebo-controlled study in milk allergic children. Allergy 43, 113-118.

Hudson MJ (1995) Product development horizons - a view from industry. European Journal of Clinical Nutrition 49, Suppl. 1, S64-S70.

Isolauri E \& Turjanmaa K (1996) Combined skin prick and patch testing enhances identification of food allergy in infants with atopic dermatitis. Journal of Allergy and Clinical Immunology 97, 9-15.

Ju HR, Okumiya M, Nishizono S, Ki M, Sugano M \& Imaizumi K (1997) Increase in degranulation of mucosal mast cells in rats sensitized with milk whey protein hydrolysates compared with native proteins. Food Chemistry and Toxicology 35, 663-668.

Kitagawa S, Zhang S, Harari Y \& Castro GA (1995) Relative allergenicity of cow's milk and cow's milk-based formulas in an animal model. American Journal of Medical Science 310, 183-187.

Madara JL (1990) Maintenance of the macromolecular barrier at cell extrusion sites in intestinal epithelium: physiological rearrangement of tight junctions. Journal of Membrane Biology 116, 177-184.

Mahé S, Messing B, Thuillier F \& Tomé D (1991) Digestion of bovine milk proteins in patients with a high jejunostomy. American Journal of Clinical Nutrition 54, 534-538.

Oldaeus G, Bjorksten B, Einarsson R \& Kjellman N (1991) Antigenicity and allergenicity of cow milk hydrolysates intended for infant feeding. Pediatric Allergy and Immunology 4, 156164. 
Pahud JJ, Monti JC \& Jost R (1985) Allergenicity of whey protein: its modification by tryptic in vitro hydrolysis of the protein. Journal of Pediatric Gastroenterology and Nutrition 4, 408-413.

Pahud JJ \& Schwarz K (1985) Oral sensitization to food proteins in animal models, a basis for the development of hypoallergenic infant formula. Production, Regulation and Analysis of Infant Formula. Proceedings of the Topical Conference, Virginia Beach, 1985, pp. 264-271. Arlington, VA: Association of Official Analytical Chemists.

Restani P, Plebani A, Velona T, Cavagni G, Ugazio AG, Poiesi C, Muraro A \& Galli CL (1996) Use of immunoblotting and monoclonal antibodies to evaluate the residual antigenic activity of milk protein hydrolysed formulae. Clinical and Experimental Allergy 26, 1182-1187.

Rodriguez P, Heyman M, Candalh C, Blaton MA \& Bouchaud C (1995) Tumour necrosis factor-alpha induces morphological and functional alterations of intestinal HT29 cl. 19A cell monolayers. Cytokine 7, 441-448.

Sollid LM, Markussen G, Ek J, Gjerde H, Vartdal F \& Thorsby E (1989) Evidence for a primary association of celiac disease to a particular HLA-DQ alpha/beta heterodimer. Journal of Experimental Medicine 169, 345-350.
Soloway P, Fish S, Passmore H, Gefter M, Coffee R \& Manser T (1991) Regulation of the immune response to peptide antigens: differential induction of immediate-type hypersensitivity and $\mathrm{T}$ cell proliferation due to changes in either peptide structure or major histocompatibility complex haplotype. Journal of Experimental Medicine 174, 847-858.

Terpend K, Boisgerault F, Blaton MA, Desjeux JF \& Heyman M (1998) Protein transport and processing by human HT29-19A intestinal cells: effect of interferon gamma. Gut 42, 538-545.

Troncone R, Caputo N, Zibella A, Russo R, Rossi M, Gianfrani C, Stern M \& Wieser H (1996) Defective 'gut processing' of gliadin in mice with graft-versus-host enteropathy. International Archives of Allergy and Applied Immunology 109, 44-49.

van Beresteijn EC, Meijer RJ \& Schmidt DG (1995) Residual antigenicity of hypoallergenic infant formulas and the occurrence of milk-specific IgE antibodies in patients with clinical allergy. Journal of Allergy and Clinical Immunology 96, 365-374.

Wahn U, Wahl R \& Rugo E (1992) Comparison of the residual allergenic activity of six different hydrolyzed protein formulas. Journal of Pediatrics 121, S80-S84.

Weiner HL (1994) Oral tolerance. Proceedings of the National Academy of Sciences USA 91, 10762-10765. 